\title{
Breast Cancer: The Best Treatment is Early Detection
}

\author{
Dra Mirta D'Ambra* \\ Chairman of World Academy Medical Sciences, Doctor in Medicine University of Buenos Aires Ministry of Health, Argentina
}

Received: April 27, 2018; Published: May 04, 2018

*Corresponding author: Dra Mirta D’Ambra, Chairman of World Academy Medical Sciences. Doctor in Medicine University of Buenos Aires Ministry of Health, Argentina

\section{Opinion}

On October 19, 1988, the World Health Organization (WHO) established World Breast Cancer Day, with the aim of raising awareness and awareness among the population about the fact that we can all help to prevent and control this disease. Breast cancer is the most frequent type of cancer in women worldwide, with a participation of 32.5 percent with respect to the total number of cases. Hereditary-familial cancers occur only between 5 and 10 percent and can be produced by different genetic mutations; the rest are presented sporadically, this means that they do not respond to a predisposition or do not have a background. According to the statistical data obtained from the Provincial Registry of Tumors of Córdoba, in the province, in the period 2004 - 2013, the incidence rate (new cases) of breast cáncer [1].

Adjusted for age was 66.9 cases per 100,000 women and the mortality rate adjusted for age was 20.6 women per 100,000 in the same period. The incidence statistics of the National Cancer Institute is a little higher: 71.1 cases per 100,000 inhabitants. This is a global problem and public health policies are dedicated to prevention and early diagnosis, with the aim of achieving an improvement in prognosis and survival. Today, with prevention which in this type of cancer consists mainly of detecting the disease in early stages - 90 percent of cases are curable [2].

\section{Risk Factor's}

According to epidemiological studies, the main risk factors for breast cancer are family history, pre-existing diseases in the breast, exposure to hormone replacements and habits and lifestyle, although on the latter the existing information is less conclusive. Healthy habits are essential to prevent any type of disease, including this type of cancer. For example, the excessive consumption of alcohol can cause one of its components, ethanol, is converted in the body into acetaldehyde, a substance that alters the DNA of cells and triggers a cascade of oxidative processes that damage its normal functioning. By this same process, changes and alterations in the absorption of nutrients, such as vitamin $\mathrm{C}$, beta-carotenes and folates, which have a protective action, can occur.
Overweight and obesity, especially in women who are in menopause, can also be predisposing factors. It happens that accumulated peripheral fat can produce exogenous estrogens (female hormones) and, in women who have a predisposition, that could lead to cellular alterations.

Adopting healthy lifestyle habits, such as not smoking, avoiding alcohol, maintaining a diet rich in fruits and vegetables and exercising can help prevent breast cancer. Another risk factor is the prolonged exposure to endogenous estrogens in women, that is, those that they themselves produce. This happens when the woman had her first menstrual period (the menarche) at an early age, if she entered the menopause late, if she did not have births or if she was exposed to exogenous hormonal treatments, such as contraceptive ingestion and hormone replacement treatments. Family history increases the risk of breast cancer two to three times. Among the genetic alterations that may occur, mutations are found in the Brca 1 and Brca 2 genes, which are associated with a very high risk of having this type of cancer. The cases of cancer caused by the mutation of these genes represent between 5 and ten percent of the total.

Health policies have encouraged screening studies in population segments corresponding to specific age segments, which is called "screening" or "screening". That is, controls aimed at women who have no symptoms and through which it is possible to observe anomalies in very early stages. This is done from the mammography, a diagnostic method that allows to discover suspicious lesions from $1 \mathrm{~mm}$. A moment of their development in which they do not give warning signals. Mammography is the screening method that has proven to be effective. Thanks to it, it has been possible to reduce mortality by 30 percent in the age group between 50 and 69 years and a 13 percent reduction in mortality in the age group between 40 and 49 years, but there has been no Modifications of reduction in mortality in women older than 70 years. To achieve success in the early detection of this disease, awareness should be raised about the importance of annual medical check-ups in the female 
population. Therefore, it is necessary that public health guarantees that the program is well organized, coordinated and sustainable over time.

In addition, it is key that in the design it is clear to which population it is directed. Likewise, it must guarantee continuity and quality in all the interventions carried out in the determined population. Who should be done or to whom is this study aimed? All women from 40 years of age should have a mammogram annually. In those women who have a family history of breast cancer and are below this age, annual controls with breast ultrasound are recommended, because at younger ages the breast tissue is more dense and makes it more difficult to visualize suspicious lesions by means of mammography. On the contrary, there are no statistical data that show that breast self-examination translates into a decrease in the risk of suffering from cancer, for which the National Cancer Institute does not recommend it.

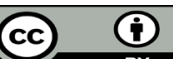

This work is licensed under Creative Commons Attribution 4.0 License

Submission Link: https://biomedres.us/submit-manuscript.php

\section{Final Suggestion}

It is very important for women to know their bodies, not to be ashamed to look at themselves, to touch themselves to detect any abnormality (breast lumps, secretions from the nipple, changes in the skin of the breast) and, if there is any suspicion or doubt, to consult to your trusted doctor. Therefore, women should acquire the habit of carrying out routine annual controls to prevent diseases or detect them early in very early stages. We have early detection methods that allow you to find cancer early and achieve better results in treatments. All women are recommended an annual consultation with their gynecologist that includes a clinical examination.

\section{References}

1. (2017) Spain Society Oncology Brest Cancer.

2. (2017) Simposium Brest Cancer San Antonio Texas.

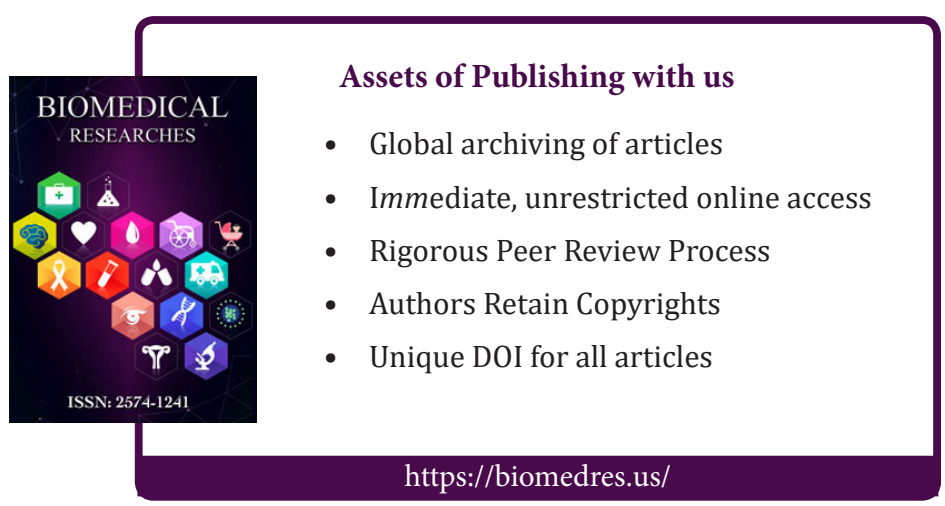

